\title{
China Elderly Care: A Confucian Legacy
}

\author{
Yutao Song* \\ The Webb Schools of California, USA \\ *Corresponding author: Yutao Song, dsong@webb.org
}

\begin{abstract}
This paper explores the Confucian roots of elderly care expectations and how these expectations may influence the current state of the elderly and elderly care in modern China. This paper posits that the outdated expectations combined with recent urbanization trends has put unrealistic pressures on society to adequately care for a rapidly aging population. Until expectations are adjusted to reflect modern day families and realities, the elderly will continue to struggle with a sense of inadequate care, which can lead to mental health issues and feelings of isolation. Once the shackles of Confucian expectations are removed, families, governments and private institutions will have the freedom to be more creative in the way they imagine solutions for elderly care.
\end{abstract}

Keywords: China elderly care; Mental health; Confucian culture; Retirement

Publication date: September 2021; Online publication: September 30, 2021

\section{Introduction}

The lack of adequate elderly care and the increasingly fragile mental state of elderly throughout China has garnered increasing attention in recent years. According to a 2013 survey of elderly mental health across China conducted by Xinli Teng, more than $10 \%$ of the more than 33,000 people surveyed over the age of 50 suffered from some kind of mental health issue. Indeed, among the nearly 550 elderlies surveyed in northwestern parts of China, over $50 \%$ reported experiencing poor mental health ${ }^{[1]}$. While these statistics alone are alarming, the fact that the elderly are receiving this kind of attention in China signals the breadth and depth of the problem. There are certainly practical issues with elderly care such as overcrowding in nursing homes and lack of nurses and doctors devoted to the growing population, but it is important to consider deeper cultural and historical aspects that could also be contributing to this problem. Digging into the changes in the way that traditional values are lived out in China's rapidly modernizing society can provide insight into some of the more fundamental causes of the mental health crisis currently unfolding among the elderly. Indeed, it would seem that the current untenable state of elderly care in China at least in part results from the tension between increasing urbanization as well as changing social norms and the ubiquity of Confucian ideals lingering throughout education and culture. The elderly people in today's China are not getting the care they expect based upon their training in Confucian principles. In general, the elderly living in urban areas often find it hard to socialize, while the elderly living in rural areas are often unaccompanied and lonely to the point where a great amount of them experience serious mental health problems ${ }^{[2]}$. The root of such issues can be traced back to Confucius and the standards he set for elderly care, a care that must be carried out with reverence and that must attend to both the physical, emotional and mental health of elderly individuals ${ }^{[3]}$. Thus, to fully understand the state of elderly in China and their care, it is important to look through the historical and cultural lens of Confucius to see how these values and expectations clash with present day realities. 


\section{The Elderly}

This paper defines elderly people as people past the age of retirement in China. In modern China, 2020 legislation set the retirement age for men at 60 and for women, at $50^{[4]}$. The reason this paper utilizes the retirement age as an indicator of old age is that past retirement age, the elderly will be in more need of "elderly care" and are more likely to experience mental health problems. According to Guilan Li and Shujing Wei, more than $50 \%$ of retired people researched were found to have some degree of mental health issues ${ }^{[5]}$. Furthermore, in mental health research regarding the elderly, studies also define elderly as over the age of 50, and since this paper references those studies to help paint the current landscape of elderly care in China, it is important to be referencing the same age group. However, in different times throughout the history of China, the retirement age differed, often due to the fact that the average life span was shorter than it is today; in some dynasties, a retirement age was nonexistent. During these points in history, this paper defines "the elderly" in ancient China as those who have children over the age of 18 because children were considered responsible for caring for their parents once they became adults, which was the age of 18 .

\section{The Analects and Filial Piety}

In China, traditional values stem from Confucius and the principles that his students codified. Confucius was a politician, teacher, and philosopher who became one of the most important persons in the history of China through the spread of his principles. His ideology formed the foundations of the ancient Chinese values throughout dynasties, even down to today. When he was alive, he had many students that observed him and recorded his sayings that have been organized in a book called "The Analects". The Analects was published roughly around 300 A.D. These sayings have been preserved well and have been used to construct the basis of Chinese culture for the past 2000 years. In fact, students of all ages, primary school, middle school and high school, learn about Confucius and Confucianism through parts of the Analects in their textbooks in all parts of China. Students are still tested on portions of The Analects on the Gaokao, the Chinese college entrance exam. Significant portions of these analects are devoted to the way that elderly should be viewed and treated by younger generations ${ }^{[6]}$. Within the 20 chapters of the Analects, the first, second and fourth chapters (Xue Er, Wei Zheng and Li Ren) all recorded teachings of Confucius about filial piety and elderly care. Some of the values stated in the Analects may seem antiquated and hard to apply in the modern context, but the idea of obedience and thoughtful care is engrained in the minds of many in their upbringings. This sense of responsibility for parents and the elderly in general continues to affect societal norms and family decision-making in the present day and so it is in this context in which Confucius' legacy in this regard will be examined.

The Analects provide a record of what Confucius taught his students about filial piety. It is these statements that shaped societal beliefs, values, norms and expectations about the elderly, their place in society and their care. One such statement was recorded by Zi You, a student of Confucius, who asked his Master - Confucius - what filial piety means. Confucius replied that, "Filial piety nowadays means the support of one's parents. But dogs and horses likewise are able to do something in the way of support; without reverence, what is there to distinguish the one support given from the other? ${ }^{[7]}$ " While this response seems like a series of riddles rather than an answer, it was understood to mean that supporting parents with food and shelter was far from enough. What distinguishes humans from animals is not the behavior, but the intention. Animals may support their parents in similar ways as humans do, but it is the reverence and the respect humans have the ability to show their parents that differ from animals. This concept remains one of the key values regarding treatment of the elderly. Children could provide elderly parents the most luxurious house and food, but without a filial heart wanting to care for their parents, the efforts would all be considered in vain. Conversely, some may lack the money to provide the best for their parents, but when they care for their elderly parents with their true heart, that is considered to be fulfilling filial piety according to 
traditional Chinese values. Another quote from The Analects reinforces this idea. Confucius responded to another student's query about what filial piety really entailed by explaining, "The difficulty is with the countenance. If, when their elders have any troublesome affairs, the young take the toil of them, and if, when the young have wine and food, they set them before their elders, is this to be considered filial piety? [8]" Confucius made it clear that simply providing food on the table does not fulfill filial piety. It is doing so with a heart that is truly loving and respecting the elderly parents and the surrounding circumstances that can be called filial piety.

\section{Filial Piety Throughout Chinese History}

While such noble standards can seem quite unrealistic and perhaps even impractical, a study of Chinese history reveals how they were very concretely worked into the fabric of governance and of daily life. In fact, starting in the Sui Dynasty around 581 A.D., the crime of "Not filial" was ruled as one of the ten worst crimes one could commit. These ten crimes were the ones that could be punished by death, and this law remained in force throughout all of the dynasties. It was only removed when the last dynasty - The Qing dynasty - ended in 1912 A.D ${ }^{[9]}$. The details of what could be classified as "Not Filial" were first recorded in the law of the Tang Dynasty, beginning around 618 A.D. One such classification was "reporting the crimes of one's parents ${ }^{[10]}$." In other words, if one's parents committed a crime and the child decided to report it to local authorities, it was the child that deserved punishment for reporting the crime of their parents. Meanwhile, even though the parents did commit a crime, when the child reported it, they could be exonerated from the punishment because they shall be considered as turning themselves in for the crime when their child reported it, with the punishment falling on the child. The punishment was severe beating among other physical tortures, which certainly made children think twice before reporting any illegal activity of a parent. The crime of treason was the only exception to this law. In other words, if one's parents were planning rebellion against the country, and the child reported it to the government, the child would not be guilty of "not filial [11]." In ancient Chinese dynasties when rules were made based on Confucian principles, the idea of loyalty underlay much of the law, with loyalty to the state and loyalty to parents being two of the most important types. In the eyes of dynasty governments, being filial was the second most important expectation just after loyalty to country based upon the degree of punishment. Loyalty to the emperor was similar to being filial to one's parents in many ways as both would require much obedience and the spirit of devotion. Therefore, most governments throughout the dynasties required their citizens to be filial by law, expecting that a sense of loyalty would grow out of this reverence and obedience. Throughout the recorded history of more than 2000 years of dynastic China, an emphasis on enforcing filial piety remained a central pillar of each emperor's rule. Even when the Qin Dynasty circa 200 A.D. distanced itself from Confucian ideals in the political arena and killed many Confucian scholars, it did not alter or interfere with the Confucian ideals regarding filial piety and the corresponding laws.

The second crime of not being filial was building a new private household while one's parents or grandparents were still alive. "Not having private money" has always been one of the ground rules of demonstrating filial piety in traditional Chinese values. While one's parents or grandparents are still alive, every direct kin should stay within the big family and let the elderly handle the money. However, this crime did not result in the most severe punishment - some dynasties had laws that regulated punishments of three years in jail for this crime, others only regulated beatings. The third crime of not being filial was not taking care of one's parents properly. If the parents reported to the government that their children did not give their best efforts to take care of them, the children would receive punishment. The punishment varied in different dynasties. In the Xia Dynasty, which was the first Chinese dynasty recorded in history, around 270 A.D., not taking care of one's parents could be punished by inking words on faces, cutting off noses or feet, and death depending on the degree of the crime ${ }^{[12]}$. In the Qing Dynasty, which was the last Chinese 
dynasty, not taking care of one's parents could be punished by beatings with huge sticks, and exile of 1000 miles from home ${ }^{[13]}$. The last law defining 'not filial' forbade children beating or cursing their parents. If one ever beat or cursed his/her parents, no matter the degree of the beating and cursing, he would be considered not filial and be punished by death ${ }^{[14]}$. Sometimes, death was not deemed enough for this crime. The child could be tortured to death and the body might be hung on city walls to warn others ${ }^{[15]}$. Considering the severity of the punishment, it is reasonable to compare this crime to that of treason "Betrayal of the country." These two seemingly vastly different types of crimes deserved the most gruesome death and shame in ancient Chinese societies because they represented a direct violation of the traditional Chinese value of "obedience." China recognized the necessity of its citizens first being taught to unswervingly obey their parents so that they would be more predisposed to submit willingly and peacefully to the Chinese monarchy. Thus, the monarchs had a vested interested in regulating and building filial piety in their subjects to ease the burden of governance and law enforcement as children grew into adults. This explains why such extreme filial piety laws remained in effect throughout the duration of the Chinese dynastic system, especially the Confucian definition of filial piety, which strongly emphasizes the importance of reverence and obedience.

These laws then led to many traditions forming around how to carry out adequate filial piety; some of these traditions even became laws. One example of a filial tradition that was codified into law around 618 A.D. during the Tang Dynasty was the tradition of "Shou Xiao" [16], which deals with honoring one's parents and other elderly relatives when they die. This law stated that when a parent died, the child must honor that parent by staying at home and regularly burning tributes such as paper flowers and money for three years. This could mean a total of 6 years if parents died at different times in addition to other time periods specified for the death of relatives of different proximities to the individual. During this time, one must stay at home, avoiding any kind of social interaction. In addition, one must not shower, cut hair or change out of the traditional clothes meant for the purpose of "Shou Xiao" for three entire years ${ }^{[17]}$. The law of "Shou Xiao" applied to government officials as well as ordinary citizens, which provides some insight into the seriousness of filial piety in ancient China. In fact, the law even regulates the punishments for government officials that chose to hide the deaths of their parents to avoid "Shou Xiao," a punishment of up to three years of imprisonment.

Stories of famous individuals living out the ideals of filial piety served as another way to establish it as a bulwark of Chinese society and values. One such story handed down throughout generations centered on a Han Dynasty emperor. This emperor personally took care of his mother when she was severely ill in bed. It is told that he mixed medicine for his mother every day and always tasted the medicine to see if it was too bitter or too hot before serving it to his mother. When his mother was at her sickest point, he only allowed himself to sleep after assuring himself that his mother was asleep, and even then, only for short amounts of time ${ }^{[18]}$. The story also emphasized how the emperor was able to rule the country well even while showing such filial devotion. During his reign, there were no famines, and the citizens were healthy and happy under his rule. This tale thus implies that if children prioritize the care of their parents, other aspects of their lives will also go well and fall into place.

One of Confucius' students, Zhong You, was also known for his dedication to filial piety. He grew up in poverty and it was told that during this time, he only allowed himself to eat vegetables that he found on the roadside, while carrying rice for tens of miles back to his parents for their consumption. After he made his wealth by working his way up through the government, he would miss his parents, saying "Even though I still want to carry rice for my parents, they are gone ${ }^{[19]}$." Confucius praised him for being truly filial "Your serving your parents can be called trying your best when they were alive and missing them while they are gone [20]." Again, this example sets a high standard for others to aim for and implies that even while depriving himself in the fulfillment of this standard, he achieved wealth and success in the long-run 
and is even remembered until today for his commitment.

Thus, filial piety was spread throughout society, from emperors to the peasants, and was seen as a unifying national value. The emperors had a vested interest in keeping such a value at the forefront of their subjects' minds given that it set a precedent of respect, self-sacrifice, and obedience. From the Tang Dynasty that began in 618 A.D. all the way through to the end of the Qing Dynasty in 1912, every single Chinese citizen was expected to be obedient to the laws and expectations around filial piety. To be a government official, one must always be filial. No matter how able a government official was deemed, once he broke the expectations of filial piety, he would face punishment. For instance, head of the cabinet in the Song Dynasty, arguably the second most powerful person in the country, was specifically required to follow the laws of "Shou Xiao" and would be evaluated for the position once they came back after three years ${ }^{[21]}$. The fact that the most powerful leaders were expected to obey the traditions of filial piety shows the esteem people held for filial piety and how it worked its way into social norms. Such obedience stemming from respect and care for parents certainly eased the governing burden for emperors and reduced the likelihood of rebellion. For instance, during the Qing Dynasty and the Yuan Dynasty, both of which had emperors of a different race than the majority Chinese, following the Confucian principles was important for political purposes, such as preventing rebellion. The emperors who came from minority groups claimed identity with the Han majority through the shared believe in Confucius. Their commitment to his values enabled them to rule China without any significant backlash during their respective reigns. Given how widespread and strict the expectations surrounding filial piety were for 1294 years, even though China has grown more modern in almost every way, the traditions of filial piety still very much influence and are part of the beliefs and value systems of Chinese citizens today.

During the transition from dynastic China to modern China, government structures changed entirely and the society progressed into a republic. Cultural changes occurred right alongside social changes. Just as the emperor of the Qin Dynasty killed Confucian scholars for total authority, getting rid of the old traditions became one of the focuses in advancing to the new modern China. Traditions such as pre-planned marriage, polygamy and many others were prohibited. However, Confucius remained a positive figure and his ideas remained relevant in modern China. From primary school to high school, multiple sections of the Analects and sayings of Confucius were added into the textbooks. In both Zhong Kao and Gao Kao, which are the qualifying tests to enter high school and college, Confucius was a frequent topic. Chinese diplomats quote Confucius often, such as “Jun Zi Tan Dang Dang, Xiao Ren Chang Qi Qi," which means that decent people do not have to worry about anything because they have no wrongdoings and can be generous, while the indecent are often miserly because of their ill intentions. Confucian ideas have become a sign of Chinese culture and are even viewed as the root of it to the extent that the ideal human being is defined by Confucian ideology: Kindness and Reverence ${ }^{[22]}$. Even today, one of the most important ways of exhibiting this kindness and reverence is through filial piety.

\section{Modernization and Urbanization of China}

When Confucius was teaching about filial piety, he based his teachings on the expectation that the children will be living in the same household with their parents. Nowadays, however, many children may live in cities hundreds of miles away from their parents due to urbanization. It is important to compare the situation of households back then and the expectations nowadays to better understand the challenges of elderly care in modern China. During Confucius' time, even though the number of people in individual households could vary greatly, there remains historical traces of the average number of people in a household dating back to 400 A.D. through the "Hu Ji" policy.

The "Hu Ji" policy was first put into place during Confucius' time. "Hu" means household, which was generally understood to include 5 people - two parents, the eldest son and potentially his wife and children 
if he married. "Ji" means place of origin. The "Hu Ji" policy allowed the government to record the number of people in each family for the convenience of taxes. However, "Hu" referred to a different number of individuals assumed to be within a single household in different dynasties. When the dynasty was richer and more stable, there tended to be more people in a household. For example, "Hu" meant 10 people in a single household in one Chinese province during the Ming Dynasty. During Confucius' time, "Hu" referred to 5 people in a single household ${ }^{[23]}$. This number assumed that the eldest son would live in his parents' house to care for them until their death. Younger children could leave the household and build their own homes, but it was considered the duty of the eldest to remain and carry out the duties of filial piety. This norm, coming out of Confucian teachings regarding filial piety, is what created the standard for threegenerational families. While it may have created slight annoyances in terms of lack of autonomy or this added responsibility regarding parents, this "Hu" standard did not materially inhibit the son's lifestyle since his work and family would be in that same town regardless. However, as China has modernized and developed sprawling metropolises that attract labor in the hopes of higher salary and better living conditions, this tradition of 'Hu' has become especially burdensome. Now, children need to choose between fulfilling their filial piety and taking a job or making a move that promises a better future for themselves and their immediate family. More and more young adults feel stuck between wanting and feeling pressured to carry out their filial duties while knowing that practicality demands a move or career change.

Despite this growing challenge, the three-generational household remains the trend even until today. In comparative terms, Chinese families have had (and continue to have) a fairly high rate of three-generation households. For example, studies show that $40-50 \%$ of urban Chinese families lived in three-generation households in the mid-1980s compared to the U.S. figure of approximately 18 percent according to research done by Xie Xiao Lin and Yan Xia to determine the differences in the attitudes towards the elderly in modern China ${ }^{[24]}$. However, the percentage of such households is declining, as Treas and Wang found that $79 \%$ of men and $65 \%$ of women aged 60 and older in the metropolitan city of Shanghai favored a separate residence. Elderly born in rural areas prefer to remain in their hometowns rather than move to the metropolis where their children may reside. This causes a problem in elderly care because of the physical distance between the elderly parents and the adult children. It reduces the ability of children to carry out the filial duties to the extent that Confucius dictated. Besides the distance, young adults also struggle to provide the necessary monetary support for their elderly parents when living in cities with high costs of living. However, even when the younger generation makes enough money to physically care for their parents, the distance still prevents the comprehensive care outlined by Confucius. A research study exploring the social constraints in modern society affecting filial piety found that China has changed so enormously in the last century that the concept of filial piety and expectations of elderly care will have to change as well. When Confucius taught his students about filial piety, his students could provide in-person care on a daily basis, while urbanization has made in-person contact much harder for many families in China, preventing the adult children from fulfilling the expectations of their parents and the standards set by Confucius.

Even in a "perfect" scenario, where the adult children have the resources to provide for their parents in big cities and the parents are willing to live in the big cities, problems still exist, preventing the carrying out of traditional Confucian elderly care. When Confucius' students, Zi You, asked what filial piety was, Confucius emphasized that adult children must provide economic support, alongside reverence and emotional support. And yet, this emotional support has proved especially difficult to provide. According to an article published in Harvard Magazine detailing the results of a field research study on elderly care, "the issue for frail elderly is really their isolation and loneliness, and desire for mobility." Picture an elderly parent in a small apartment in Shanghai, living with their child, son or daughter-in-law and grandchild. The husband and wife leave for work, the child goes to school, and the elderly individual is left alone from breakfast to dinner time. Even after school, the child plays music and video games that the elderly cannot 
enter into or understand. This is the reality of some of the three-generational households in big cities such as Shanghai and Beijing. It is not strange then that some of the elderly would prefer assisted living in elderly care facilities rather than living with their children and grandchildren. However, this goes against Confucian principles for carrying out adequate elderly care and goes to show how difficult it is to carry out in China's rapidly modernizing society.

Indeed, despite the changing circumstances arising from modernization and urbanization, in many Chinese families, adult children may feel that they are breaking a Confucian expectation to take care of their parents at home if they put them into group care. Placing one's parents in elderly care facilities does not seem to fulfill the Confucian requirement of self-sacrifice and complete mental and physical care because it implies that the children are not really paying attention to their parents, not providing for them with their loving heart. However, it has become clear that the pace of urban life and its requirements also prevent this kind of total care even if parents live with their children. The problem, then, seems to lie within the expectation itself. It is simply unrealistic for much of the population to really follow the rules set by Confucius. Under such exacting expectations set by ancestors and the elderly themselves, it leaves little room for adult children to adapt to changing times and still provide adequate care. And yet, a rethinking and reimagining of the system is critical if the elderly is to be physically and emotionally care for in modern China.

\section{The Challenges in Creating a Modern Solution to Elderly Care}

Part of the challenge in transitioning to more of a nursing home model for elderly care in China is the current overcrowding, under-resourced and understaffed state of the few nursing home facilities already existing. This lack of quality facilities means that children would be especially looked down upon if they allow their parents to go to such a place as they age. While the elderly care policy and provisions in China have been transforming gradually, until recently, institutional elderly care was rare and limited to the socalled "Three No's" - people with no children, no income, and no relatives. Such elderly were often public welfare recipients. Institutionalized elders were stigmatized. In the mid-1990s, China implemented reforms to decentralize the operation and financing of state welfare institutions. Since then, these institutions have shifted their financial reliance from public funding to more diversified revenue sources, including privately paying individuals. Elderly care homes have proliferated, primarily in the private sector in urban areas. In recent years, the Chinese government has increased its efforts to build residential elder care services by actively promoting the construction of senior housing, homes for the aged, and nursing homes. Such efforts are gradually destigmatizing the idea of elderly care facilities, but there is still much work to be done in terms of building more quality facilities and building acceptance for such forms of elderly care in mainstream culture.

However, even with the efforts the government is making for nursing institutions many governmentowned nursing facilities remain underfunded and understaffed. There are not enough nurses, and the facilities are often overcrowded. Lin, a 53-year-old elderly care worker in the central city of Wuhan, has been in the industry for over five years. She was so busy that the interviewer could barely talk to her during her work hours. The pressure and workload these nurses face uncontrolable. There are often too many elderly people that require individual attention. What has kept her doing this job is the moral obligation she feels towards this demographic rather than the salary, which is meager at best. It is simply unrealistic for several nurses to tend to several dozen elderly people. Lin herself admitted that her salary did not match up with the workload she had to endure, and one of the reasons she had not left for a much easier job, like a nanny, was that she felt somewhat responsible for the elderly people, as they absolutely depended and relied on the nurses and the facility. 
Given such conditions, it is simply unrealistic for thoughtful individual care, as the number of the elderly people is often multiples of the number of nurses, which means that the elderly people may not receive support designed for their own special needs. The nursing facilities have the potential to provide a space for elderly to make friends and build relationships that would support their mental health, but this needs to be coupled with individual health plans to support their various physical needs. This combination is needed before elderly care facilities could hope to live up to Confucian principles of elderly care.

One such well-rounded solution has been proposed in the relatively central Huayang Subdistrict of Shanghai, where a majority of senior residents have expressed strong interest in more day care options, door-to-door services, and activity space within their community, according to Chen Ying. Of the more than 62,000 residents in Huayang Subdistrict, some 42\% are aged 60 or above. Mao Xuezhen, an 83-yearold retired doctor, was among the first to take advantage of the care center. After hip surgery, she moved into the community's nursing home to recover. "After my husband passed away three months ago, I was alone at home," Mao said. At Huayang Integrated Elder Care Center, Mao enjoys being surrounded by others from her generation and looked after by nurses and certified care workers. "It's much better than staying at home with a nanny," she said.

Apart from long-term care, the facility also offers day care for seniors and short-term services for those recovering from medical procedures. Huayang Integrated Elder Care Center also provides family support, training locals how to look after their elderly relatives and renting out health care equipment. Other senior residents of Huayang Subdistrict who don't require regular care can still benefit from the center, where they can play musical instruments, do tai chi, or simply enjoy a cup of coffee while catching up with their neighbors. The key is that such facilities are not far from city centers given that "seniors don't want to live far away from their families," a worker at the Huayang Center, Chen Ying, explained. "We established built-in elder care facilities and services, and senior residents are also getting the emotional support they need from the surrounding community, so that they're able to enjoy retirement in a familiar setting, in the company of their loved ones." Such arrangements could provide the ideal solution for elderly care in modern China and yet the number required to care for China's rapidly increasing elderly population remains a challenge.

In 2005, Shanghai was still advocating for a largely family centered care model that they termed: "907-3": $90 \%$ of seniors living independently or being cared for by their families, $7 \%$ needing home-based care services, and 3\% requiring full-time institutional care. This could be a usable model for some of the cities that have gone through or are going through the process of urbanization, although the percentages sill leave room for optimization. Systemizing the organization of elderly care and personalizing the actual care services are two of the most important aspects to be addressed. In big cities like Shanghai itself, having the elderly parents move in most likely means that the adult children are surviving with some extra money they could spend on the elderly care services. This system provides a great opportunity for the elderly people to enjoy their life with their peers, while not creating unrealistic pressure upon the adult children. It does not fit the description of elderly care that Confucius proposed thousands of years ago, but it could fulfill the essence of it by providing caring physical and emotional support. Clinging to ancient standards is likely only to lead to more frustration on the part of children and isolation on the part of the elderly. Adapting to the current situation and solving the elderly care crisis is the most important, and this system proposed in Shanghai is no doubt a meaningful try.

Thus, in understanding and addressing the current challenges surrounding elderly care in China, it is essential to study and consider its development throughout China's history. Confucius set the standards for elderly care that were recorded by his students in The Analects. These standards continued to govern expectations for elderly care throughout the Dynastic China and even down until today. And yet China's recent urbanization and modernization towards the end of the $20^{\text {th }}$ century have put a strain on children's 
ability to carry out such expectations that involve showing the utmost obedience, reverence along with physical and emotional care, and often require 3-generational living arrangements. Due to urbanization, many adult children leave their rural hometowns for the big cities to live on their own. Meanwhile, their elderly parents still hold the same expectations for elderly care even though their children may be thousands of miles away from them. This creates conflict as expectations clash with reality. Indeed, Confucius set the standards for elderly care on the basis of children living in the same household or at least near their parents. The traditional Confucian expectations have not changed even as it has become more common for adult children to live in different cities from their parents. There are many practical components that can be built into a solution to this elderly care challenge. Governments can encourage and fund more communal living arrangements for elderly as well as state-of-the-art nursing care facilities. Private companies can also fill the void of creating quality care facilities. However, for these practical solutions to take hold, it is important that all generations across China recognize the history of elderly care expectations and accept that such expectations much change to match the realities of a modern China. It is essential to identify and appreciate the Confucian roots while finding new ways to care for elderlies' physical and emotional needs. Such solutions must be deemed culturally acceptable in addition to being effective. A shift in the way that Confucian principles regarding filial piety are carried out is necessary for China as a nation and a culture to conscientiously and effectively care for its rapidly aging population.

\section{Disclosure statement}

The author declares no conflict of interest.

\section{References}

[1] Cao H, 2018, Exam Preparation Strategy for the New Classic Reading "The Analects of Confucius" in Beijing College Entrance Examination. IResearch: https://www.ixueshu.com/document/90e2dbb 65f479b6276f0331cfc58808e318947a18e7f9386.html.

[2] Chen L, Yukuan D, 2016, “Zhong Guo Gu Dai Hu Ji Zhi Du De Li Shi Fa Zhan Yu Xian Shi Zuo Yong.” Lan Ti Shi Jie. https://doi.org/10.16565/j.cnki.1006-7744.2016.07.47.

[3] Chen L, Yukuan D, 2016, “Zhong Guo Gu Dai Hu Ji Zhi Du De Li Shi Fa Zhan Yu Xian Shi Zuo Yong.” Lan Tai World, 117-118. https://doi.org/10.16565/j.cnki.1006-7744.2016.07.47.

[4] Guilan L, Shujing W, 2004, "Ying Xiang Li Tui Xiu Lao Nian Ren Xin Li Jian Kang Shui Ping De Xiang Guan Yin," Chinese Journal of Behavioral Medical Science 2004, 13(3), DOI: 10.3760/cma.j.issn.1674-6554.2004.03.054.

[5] Fan Y, 2020, "Shanghai Touts Community Integration as Model for Elder Care," Sixth Tone, October 22, 2020, http://www.sixthtone.com/news/1006327/shanghai-touts-communityintegration-as-model-for-elder-care.

[6] Huang J, 2015, The Law of Respecting the Elderly in Ancient China. CNKI, (4): 43-49.

[7] Jia L, 2008, On the Crime of Unfilial Piety in Qin and Han Dynasties. CNKI, (01):20.

[8] Keong-Suk P, 2013, "Consecrating or Desecrating Filial Piety?: Korean Elder Care and the Politics of Family Support." Development and Society 42, 2: 287-308. Accessed June 5, 2021. http://www.jstor.org/stable/deveandsoci.42.2.287.1

[9] Legge J, 2021, “The Analects ( Lun Yu ).” James Legge's Translation of the Analects. Accessed June 5, 2021. http://camcc.org/_media/reading-group/lunyu/lunyu-en.pdf

[10] Li, Z, 2016, On the Evolution of "Three Years of Funeral" in the Jin and Tang Dynasties. CNKI, (04): 011. 
[11] Li Z, Cuiling L, Ye Tao, 2013, "Lun Gu Dai Xiao Dao Si Xiang, Xiao Dao Zhi Du Ji Qi Xian Dai Jia Zhi." Academic Exchange 04.

[12] Ma J, Ding Z, 2005, “Lun Zhong Guo Gu Dai Shou Sang Zhi Du De Fa Lv Hua.” Thinking, 11924.

[13] Ming Y, 2021, "China to Raise Retirement Age to Offset Funding Shortfall." Voice of America, March 17, https://www.voanews.com/east-asia-pacific/voa-news-china/china-raise-retirement-ageoffset-funding-shortfall.

[14] Ren M, 2017, “Ru Jia De Yang Lao Si Xiang Ji Qi Xian Dai Yi Yi.” Journal of Hengshui University 19(6).

[15] Shaw J, 2019, "The Coming Eldercare Tsunami." Harvard Magazine, December 17, 2019. https://harvardmagazine.com/2020/01/elder-care-china.

[16] Shi T, 2019, "Shi Lun Kong Zi Yu Lao Zi Ji Yu Li Xiang Ren Ge Su Zao De De Yu Si Xiang Ji Qi Xian Dai Jia Zhi." Journal of Shandong Youth University of Political Science 35, (06). https://doi.org/10.16320/j.cnki.sdqnzzxyxb.2019.06.008.

[17] Tang Y, Hooyman N, 2018, "Filial Piety, Living Arrangements, and Well-Being of Urban Older Adults in Southern China." Asian Social Science 14, (6): 21. https://doi.org/10.5539/ass.v14n6p21.

[18] Tian X, 2014, "Cong Han Xian Di Wei Mu Wei Yao Qian Shuo 'Xiao.”” Archives, 46-47.

[19] Tian Z, Bing L, 2020, “Song Dai Zai Xiang Ding You Qi Fu Kao Lun.” Song Shi Yan Jiu Lun Cong, 43-65. https://doi.org/10.16764/b.cnki.ssyjlc.2020.0003.

[20] Xie X, Yan X, 2005, "Attitudes Toward the Elderly in China: Comparison of College Students and Baby Boomers." International Journal of Sociology of the Family 31, (2): 145-58. Accessed June 5, 2021. http://www.jstor.org/stable/23070653.

[21] Teng X, Wang J, Zhan J, et al., 2015, “Zhong Guo Zhong Lao Nian Ren Xin Li Jian Kang Xian Zhuang," Zhong Guo Lao Nian Xue Za Zhi,” (35), doi: 10.3969/j. issn. 1005-9202. 2015. 03. 100.

[22] Xu Min, 2014, Research on the Crime of Unfilial Piety in Chinese Feudal Society. CNKI, (15).

[23] Yan Z, 2021, “China's Elder Care Industry Can't Run on Moral Obligation Alone." Sixth Tone, http://www.sixthtone.com/news/1006830/chinas-elder-care-industry-cant-run-on-moralobligation-alone.

[24] Zhan, Heying J, Rhonda J. V., 2003, "Gender and Elder Care in China: The Influence of Filial Piety and Structural Constraints." Gender and Society 17(2): 209-29. Accessed June 5, 2021. http://www.jstor.org/stable/3594688. 